\title{
Labor-dependent Capital Income Taxation That Encourages Work and Saving
}

\author{
Sagiri Kitao* \\ Federal Reserve Bank of New York
}

February 1, 2010

\begin{abstract}
We propose a simple mechanism of capital taxation which is negatively correlated with labor supply. We use a life-cycle model of heterogeneous agents and show that the tax scheme provides a strong work incentive when households possess large assets and high productivity later in the life-cycle, when they otherwise would work less. The system also adds to the saving motive and raises aggregate capital. The increased economic activities expand the tax base and the revenue neutral reform results in a lower average tax rate. The reform improves long-run welfare and the majority of current generations would experience a welfare gain from a transition to the reformed system.
\end{abstract}

Keywords: Capital income taxation, life-cycle J.E.L. classification codes: E62, H24, H31

${ }^{*}$ I thank Andy Abel, Juan Carlos Conesa, Selahattin İmrohoroğlu, Dirk Krueger, Ayşegül Şahin, Gianluca Violante and participants at various seminars for their valuable comments. All errors are my own. The views expressed in the paper are those of the authors and do not necessarily reflect those of the Federal Reserve Bank of New York or the Federal Reserve System. The author can be reached at sagiri.kitao@gmail.com. 


\section{Introduction}

How we should tax capital income is a question that never ceases to interest economists. Ever since the seminal work of Judd (1985) and Chamley (1986) that demonstrated the optimality of zero capital income tax using a neoclassical growth model populated by infinitely-lived agents, numerous papers followed and explored the topic, while reaching a variety of conclusions. On one hand, authors including Lucas (1990), Atkeson, Chari, and Kehoe (1999) and Jones, Manuelli, and Rossi (1993) concur with Chamley and Judd and demonstrate robustness of the zero capital tax result in extended models. On the other hand, Hubbard and Judd (1986), Aiyagari (1995) and İmrohoroğlu (1998) argue that departure from the complete market assumption calls for the role of a positive capital income tax in a model with uninsurable idiosyncratic income risk and borrowing constraints. More recently, Erosa and Gervais (2002) and Garriga (2003) show theoretically that in a life-cycle model of overlapping generations non-zero capital income tax is in general optimal at least if the tax rates cannot be conditioned on the age of households. Conesa, Kitao, and Krueger (2009) quantitatively characterize the optimal combination of capital and labor income tax using a flexible form of taxation and find the optimal capital income tax rate is significantly positive at $36 \%$.

What is common across the existing papers is that the rate of capital income taxation is assumed to be either a constant (i.e. proportional taxation) in most cases or some progressive function of capital income or total income. ${ }^{1}$ What we propose in this paper is to introduce a simple form of interaction between capital taxation and labor supply, in which the rate of capital income tax falls in labor supply through its dependence on observed labor income. We demonstrate that introducing labordependence in capital taxation can induce more efficient intertemporal allocation of labor supply over the life-cycle, stimulate economic activities, raising aggregate labor supply, capital, output and consumption, and improve welfare in both short and long-run.

In theoretical studies Atkeson et al. (1999), Erosa and Gervais (2002) and Garriga (2003) show that the optimal tax rates on capital and labor will vary by age in general in a model where the optimal consumption-work profile over the life-cycle is not constant. In the absence of age-dependent taxation, Conesa et al. (2009) show the optimality of a positive capital tax, arguing that it can mimic the role of optimal age-dependent labor taxes. We show that the labor-dependent capital taxes can

\footnotetext{
${ }^{1}$ Nonlinear income taxation had not been studied extensively until recently. See, for example, Bohacek and Kejak (2004), Conesa and Krueger (2006), Conesa et al. (2009) and Gervais (2009), who study non-proportional taxation and the optimal progressivity of income taxation.
} 
approximate the optimal age-dependent taxation in both labor and capital income and also circumvent negative consequences implied by a high capital tax proposed in Conesa et al. (2009). The reward of additional work is not only the wage net of a labor tax, but also the reduction in capital taxes as a result of its negative labordependence. This creates the profile of effective wage rates that vary by age as the amount of saving changes, inducing more work effort at middle to old ages, in the same way as the optimal age-dependent labor taxes do. The rise in the capital tax when the labor income falls makes the future consumption increasing more costly and raises the opportunity cost of leisure, which approximates the shape of optimal age-dependent capital taxation that increases in age.

The tax system implies a low capital tax for middle-age households with high labor income. They have a strong saving incentive for retirement, which becomes intensified by the higher after-tax return from savings. More saving, again, will reinforce the work incentive since it raises the effective wage from extra work. There are, however, possible counter effects that may offset the positive effects. First, the higher level of saving and consumption strengthens the income effect and may discourage work effort. Second, general equilibrium effects can negatively affect the saving incentives. For example, if the increase in labor supply dominates the rise in capital, whether in the final state or during the transition, interest rate falls and offsets the effect of a positive capital income tax. Third, providing work incentives through the capital tax reform may negatively affect the fiscal balance and call for distortionary taxation on other sources of income, which may counteract the positive incentive effects.

Therefore, fully understanding the effects of the proposed reform requires a quantitative general equilibrium model that incorporates these channels interacting with each other. We follow the tradition of the life-cycle model of Auerbach and Kotlikoff (1987), which is one of the workhorse models in macroeconomic policy analysis and has been extensively used in quantitative fiscal studies including Altig et al. (2001), Ventura (1999), Domeij and Heathcote (2004) and Nishiyama and Smetters (2005), to name a few. We will first build and calibrate a model that matches key features of the U.S. economy, which we use as a benchmark to run the policy experiments. After we analyze long-run effects of a reform by comparing two steady state economies, we compute the transition dynamics to study the effects on welfare and economic variables in a short-run. In the baseline reform, aggregate capital and labor will rise by 6.1 and $4.3 \%$ in the long-run. Most of the increase in labor supply comes from the additional work provided by middle to old-age households with high labor productivity, therefore raising the average labor productivity. Given the increased economic activities, the tax base will significantly expand, resulting in a lower av- 
erage income tax rate. In the long-run, the system brings a welfare gain of $1.6 \%$ in consumption equivalent variation. In the short-run, more than $95 \%$ of the currently alive generations will experience a welfare gain.

The rest of the paper is organized as follows. Section 2 presents the model. Section 3 outlines the calibration, with the results presented in section 4 In section 5 we discuss interpretation of the results and present sensitivity analysis. Section 6 concludes.

\section{Model}

\subsection{Demographics}

In each period the economy is populated by overlapping generations of households of age $j=1,2, \ldots, J$. The new cohort is larger than the previous one by a fraction $n$. Life-time is uncertain and agents of age $j$ face a conditional probability $s_{j}$ to survive until the next period. Accidental bequests are distributed in a lump-sum fashion across households currently alive and denoted by $b$. At an exogenous age $j_{R}$, agents retire and start to receive social security benefits $s s$.

\subsection{Technology}

A representative firm produces output according to a constant returns to scale technology: $Y=F(K, L)=A K^{\alpha} L^{1-\alpha}$, where $K$ and $L$ are aggregate capital and labor and $\alpha$ is the capital share. The constant $A$ normalizes units in our economy. Capital depreciates at rate $\delta$. The firm rents capital and labor efficiency from households in competitive markets, where factor prices $r$ and $w$ are equated to the marginal productivities.

\subsection{Endowment and preference}

Every period agents are endowed with one unit of time, which they can spend supplying labor in a competitive market or consuming leisure. New households enter the economy with no assets, besides a lump-sum transfer from accidental bequests.

Labor income is given as $\varepsilon_{j} e l w . \varepsilon_{j}$ captures age-dependent deterministic labor productivity with $\varepsilon_{j}=0$ for $j \geq j_{R}$. e represents an idiosyncratic productivity shock, which follows a Markov process. $l$ is the hours of work that agents choose optimally. 
Preferences over the sequence of consumption and leisure $\left\{c_{j},\left(1-l_{j}\right)\right\}_{j=1}^{J}$ are represented by a time-separable utility function $E\left\{\sum_{j=1}^{J} \beta^{j-1} u\left(c_{j}, 1-l_{j}\right)\right\}$, where $\beta$ is the time discount factor. Expectations are with respect to the stochastic process governing idiosyncratic labor productivity and mortality.

\subsection{Government}

The government taxes consumption and income from labor and capital in order to finance an exogenous amount of public expenditures $G$. The consumption tax is proportional at rate $\tau_{c}$ and the income tax is given by a function $\mathcal{T}\left(y_{L}, y_{K}\right)$, where $y_{L}$ and $y_{K}$ represent labor and capital income. We impose a balanced budget every period. The government also operates a self-financed pay-as-you-go social security system, represented by a payroll tax $\tau_{s s}$ on labor income and a benefit $s s$ for each retiree.

\subsection{Market structure}

There is no market for state-contingent assets. Households can only purchase and accumulate a positive amount of one-period riskless asset that pays at the market interest rate.

\subsection{Household problem}

The households' problem is computed recursively. Agents are heterogeneous in three dimensions in terms of age $j$, assets at the beginning of a period $a$ and idiosyncratic labor productivity e. A household's problem is to solve:

$$
V_{j}(a, e)=\max _{c, l, a^{\prime}}\left\{u(c, 1-l)+\beta E V_{j+1}\left(a^{\prime}, e^{\prime}\right)\right\}
$$

subject to

$$
c+a^{\prime}=(1+r)(a+b)+\varepsilon_{j} e l w+T, \quad a^{\prime} \geq 0, \quad l \in[0,1]
$$

where $T$ represents the net transfer from the government.

$$
\begin{aligned}
& T=-\tau_{c} c-\mathcal{T}\left(y_{L}, y_{K}\right)-\tau_{s s} y_{L} \text { if } j<j_{R} \\
& T=-\tau_{c} c-\mathcal{T}\left(0, y_{K}\right)+s s \text { if } j \geq j_{R}
\end{aligned}
$$

The labor income and capital income are given as $y_{L}=\varepsilon_{j} e l w$ and $y_{K}=r(a+b)$. 


\subsection{Competitive equilibrium}

A competitive stationary equilibrium, for a given set of fiscal variables $\left\{G, \tau_{c}, \tau_{s s}\right\}$, is households' decision rules $\left\{c_{j}, l_{j}, a_{j}\right\}_{j=1}^{J}$, factor prices $\{r, w\}$, income tax function $\mathcal{T}$, social security benefit $\{s s\}$, a lump-sum transfer of accidental bequests $\{b\}$ and the measure of households $\left\{\mu_{j}(a, e)\right\}$ in each state that satisfy the following conditions.

1. Households' allocation rules solve the optimization problems defined in section 2.6

2. Factor prices are determined competitively, i.e. $r=F_{K}(K, L)-\delta$ and $w=$ $F_{L}(K, L)$.

3. The labor and capital markets clear, i.e. $L=\sum_{j} \sum_{a} \sum_{e} \varepsilon_{j} e l_{j}(a, e) \mu_{j}(a, e)$ and $K=\sum_{j} \sum_{a} \sum_{e}\left[a_{j}(a, e)+b\right] \mu_{j}(a, e)$.

4. The income tax function satisfies the government budget constraint. ${ }^{2}$

$$
G=\sum_{j} \sum_{a} \sum_{e}\left[\tau_{c} c_{j}(a, e)+\mathcal{T}\left(y_{L, j}(a, e), y_{K, j}(a, e)\right)\right] \mu_{j}(a, e)
$$

5. The social security system is self-financed.

$$
s s \sum_{j \geq j_{R}} \sum_{a} \sum_{e} \mu_{j}(a, e)=\sum_{j<j_{R}} \sum_{a} \sum_{e} \tau_{s s} \varepsilon_{j} e l_{j}(a, e) w \mu_{j}(a, e)
$$

6. The final good market clears.

$$
C+K^{\prime}+G=Y+(1-\delta) K,
$$

where $K^{\prime}$ denotes aggregate capital in the next period and $C$ aggregate consumption.

7. The lump-sum bequest transfer is consistent with the amount of assets left by the deceased.

$$
b=\sum_{j} \sum_{a} \sum_{e} a_{j}^{\prime}(a, e)\left(1-s_{j-1}\right) \mu_{j}(a, e)
$$

\footnotetext{
${ }^{2}$ To satisfy (5), at least one of the parameters that define the income tax function must adjust. This parameter depends on the form of the tax schedule in the benchmark and reformed tax system, which we discuss more in detail in section 3 and 4
} 
8. The distribution $\mu_{j}(a, e)$ is time-invariant. The law of motion for the distribution of households over the state space satisfies $\mu_{j}(a, e)=R_{\mu}\left[\mu_{j}(a, e)\right]$, where $R_{\mu}$ is a one-period transition operator on the distribution.

\section{Calibration}

This section presents the parametrization of the model. The values of calibrated parameters are summarized in Table 1.

Demographics: The model period is one year. Agents enter the economy at age 20 and live up to the maximum age of 100. Age-specific surviving rates are based on Bell and Miller (2002). The population grows at $1.2 \%$.

Preferences: Households rank a bundle of consumption $c$ and leisure $(1-l)$ according to the period utility function defined as

$$
u(c, 1-l)=\frac{\left[c^{\nu}(1-l)^{1-\nu}\right]^{1-\sigma}}{1-\sigma} .
$$

The parameter $\nu$ determines the weight on utility from consumption relative to that from leisure, which is calibrated so that one-third of disposable time is spent on the market work on average. We set $\sigma=4$, which implies the intertemporal elasticity of substitution of about 0.5 , in the middle of the range of micro estimates in the literature (see Attanasio 1999, for a survey). ${ }^{3}$ The subjective discount factor $\beta$ is set at 1.008 so that the model generates a capital-output ratio of 3 .

Endowment: Age-dependent labor productivity $\varepsilon_{j}$ is based on Hansen (1993). The idiosyncratic component $e$ is specified as a simple first-order autoregressive process with a persistence parameter $\rho=0.94$ and a variance of the white noise $\sigma_{e}^{2}=0.02$, which lie in the range of estimates in the literature (see, for example, Healthcote et al, 2004). We use the method of Tauchen (1986) to approximate the process by a transition matrix defined over five grid points. Agents make a random draw of $e$ from its stationary distribution as they enter the economy at age $j=1$.

\footnotetext{
${ }^{3}$ Note that the coefficient of relative risk aversion is given as $1-\nu(1-\sigma)=2.1$ with calibrated $\nu=0.368$.
} 
Technology: The capital share is set at 0.33 and the depreciation rate $\delta$ at $7 \%$, implied by the law of motion for the capital in the steady state, $\delta=\frac{X / Y}{K / Y}-n$ with the target investment-output ratio $X / Y$ of $25 \%$ and capital-output ratio $K / Y$ of 3.0. The TFP parameter $A$ is normalized so that the average per-capita income is 1.0 .

Government: The government expenditures are set at $20 \%$ of the total output in the benchmark economy. The consumption tax rate is set at $5 \%$.

In the benchmark economy, the income tax is given by a non-linear tax function of total income, $y=y_{L}+y_{K}$. The income tax function consists of two parts, a non-linear progressive income tax and a proportional income tax. The non-linear part approximates the progressive income tax schedule in the U.S. following the functional form estimated by Gouveia and Strauss (1994), while the proportional part stands in for all other taxes, that is, non-income and non-consumption taxes, which for simplicity we lump together into a single proportional tax $\tau_{I}$ levied on total income. The functional form is given as

$$
\mathcal{T}(y)=\kappa_{0}\left\{y-\left(y^{-\kappa_{1}}+\kappa_{2}\right)^{-1 / \kappa_{1}}\right\}+\tau_{I} y .
$$

Parameter $\kappa_{0}$ is the limit of marginal taxes in the progressive part as income goes to infinity, $\kappa_{1}$ determines the curvature of marginal taxes and $\kappa_{2}$ is a scaling parameter. To preserve the shape of the tax function estimated by Gouveia and Strauss, we use their parameter estimates $\left\{\kappa_{0}, \kappa_{1}\right\}=\{0.258,0.768\}$ and choose the scaling parameter $\kappa_{2}$ such that the share of government expenditures raised by the progressive part of the tax function equals $65 \%$. This matches the fraction of total revenues financed by income tax (OECD Revenue Statistics). The proportional tax rate $\tau_{I}$ is set so that the overall government budget is balanced.

The social security tax $\tau_{s s}$ is set at $10.6 \%$. The pension benefit ss that balances the social security budget (6) is $46 \%$ of the average earnings in the benchmark economy, close to the average replacement rate of the U.S. social security system.

\section{Numerical results}

In this section, we investigate the effect of a labor-dependent capital income tax. 


\subsection{Computational experiment}

We consider the following simple form of labor-dependent capital taxation, where the capital income tax rate is a linearly decreasing function of labor income. ${ }^{4}$

$$
\tau_{k}\left(y_{L}\right)=\phi_{0}+\phi_{1} y_{L}
$$

where $\phi_{0}$ and $\phi_{1}<0$ are the policy parameters to be specified. Labor income is subject to the same tax function as in the benchmark system. The total income tax liability of a household is given as

$$
\mathcal{T}\left(y_{L}, y_{K}\right)=\tau_{k}\left(y_{L}\right) y_{K}+\kappa_{0}\left\{y_{L}-\left(y_{L}^{-\kappa_{1}}+\kappa_{2}\right)^{-1 / \kappa_{1}}\right\}+\tau_{I} y_{L},
$$

where the parameters $\left\{\kappa_{0}, \kappa_{1}, \kappa_{2}\right\}$ take the same values as in the benchmark. The tax reforms are revenue neutral, that is, the amount of expenditures that the has to be financed remains the same and we let the proportional tax rate $\tau_{I}$ on labor income adjust to balance the government budget. For the retired agents who no longer work, we assume that the tax function is the same as in the benchmark and their capital income is subject to the original tax function specified in (10) with the same parameter values that are used in the benchmark.

Parameters in the capital tax function (11) are set so that if one's labor income is at the average level of the benchmark economy $(\$ 35,000)$, the capital tax rate will be the average income tax rate that prevailed in the benchmark $(22.0 \%)$. The tax rate linearly falls in labor income and it can go negative, i.e. capital subsidy. For normalization, we express the labor income as its ratio to the average labor income in the benchmark and the capital income tax as a function of this ratio. With this function, we consider the slope coefficient $\phi_{1}$ at -1.0 and the intercept $\phi_{0}$ is set so that the tax function passes through the reference point of the tax rate of $22 \%$ for labor income of $\$ 35,000$. The capital income function is displayed in 1 . We also consider alternative tax functions with different slopes and levels in section 5.3

\subsection{Aggregate effects}

The effects of the tax reform on aggregate variables are summarized in Table 2 . The negative dependence of capital income tax on labor income provides a large incentive for work and saving. Aggregate capital and labor supply increase by 6.1

\footnotetext{
${ }^{4}$ The critical incentive effects are driven by the negative relationship between capital income tax and labor supply. Having the tax, however, directly depend on hours of work may not be a practical policy given the difficulty of verification and we chose to use labor income as an argument.
} 
and $4.3 \%$ respectively, and the aggregate consumption by $6.1 \%$. The rise in capital dominates the rise in labor supply and the interest rate falls slightly given the higher capital-labor ratio.

One may be concerned that the reform may negatively affect tax revenues and require a hike in the labor income tax to finance the given government expenditures. It turns out, however, that the proportional tax $\tau_{I}$ on labor income barely changes and it remains at $5.4 \%$. As we discuss more in section 4.3 , it implies lower marginal tax rates on labor income, especially for households with more wealth, since the capital income is excluded from the tax base that is subject to the progressive tax function. As shown in Table 2, the average income tax rate defined as the total tax payment divided by the sum of total labor and capital income, declines by 1.1 percentage points in the reform economy, because increased economic activities significantly expand the income tax base. Note that we assumed the same tax function for retirees as in the benchmark and the average tax rate on their capital income will slightly increase from 13.3 to $13.9 \%$, since they have a much higher level of wealth at the time of retirement and the progressive tax implies a higher average rate.

The last row of Table 2 shows the long-run welfare effect of a reform, which is expressed in terms of consumption equivalent variation from a perspective of a new-born agent. It is a percentage change in consumption across all possible states in the benchmark economy that is required to make an agent as well off as in the reform economy. A positive number implies a welfare improvement by the reform. The large increase in consumption while being offset by the added disutility by more work leads to a net welfare gain of $1.6 \%$. The direct benefit of the reform falls on agents with high labor productivity and labor income who enjoy higher aftertax return from savings. It is, however, not just the individuals in states of high productivity and large assets that benefit from the reform and those with a low level of assets and productivity will also gain since the wage increases. The analysis on who gains and loses among the currently alive generations requires computation of transition dynamics, which we present in section 4.4

\subsection{Effects on life-cycle profiles}

Figure 2 displays the profile of labor supply and savings during the working period and consumption and wealth over the entire life-cycle in the benchmark and the reform economy. ${ }^{5}$ Figure 3 displays the average of the total income tax rates by age

\footnotetext{
${ }^{5}$ Saving is defined as the change in wealth across two periods.
} 
across working-age households in the two economies as well as the decomposition of the tax rates in the reform economy, distinguishing between the capital and labor income tax rates. ${ }^{6}$ As Figure 2(a) shows, the effect on labor supply is not uniform and a large increase comes from workers in middle to old ages. The difference can be explained by a combination of different factors. First, households have a stronger incentive to increase labor supply when the gain is larger (or the loss is smaller) by doing so, that is, when they have more wealth and higher capital income. ${ }^{7}$ Second, after the peak of labor income, the capital tax starts to rise sharply as shown in 3(b). The shape of the capital tax rates is the mirror image of the labor income profile, given the negative dependence, which implies a higher cost of future consumption and makes leisure increasingly more costly as households age. Lastly, the marginal tax rate on labor income is lower for older households. Isolating capital income from the progressive tax base will reduce the marginal labor income tax rate, especially for older households with more wealth. ${ }^{8}$

Because of the non-uniform change in labor supply across age groups and the decomposition effect, the average labor productivity per worker is higher. As shown in Table 2, the aggregate labor supply increases by $4.3 \%$, which is greater than the rise in work hours of $3.6 \%$. The capital income tax rate is lower for households between late 20s and late 40s, when households undertake massive life-cycle savings to accumulate wealth for retirement. As shown in Figure 2(b), it provides the households in this age group with additional saving motives to exploit the lower tax on saving returns and households will own higher wealth for the rest of the life-cycle as shown in Figure 2(d). As we will discuss in section 5.1, the shape of the capital taxes after the peak of labor income resembles the optimal profile of age-dependent capital income tax when the government is allowed to condition tax

\footnotetext{
${ }^{6}$ The shapes of the tax profile are nearly identical for retirees in two economies and not displayed here. Also note that we cannot do the decomposition analysis for the benchmark since the income tax function does not distinguish the sources of income.

${ }^{7}$ This age-dependent effects approximate the role of optimal age-dependent labor taxes. See section 5.1 for more details on the relation to the literature of optimal income taxation in a life-cycle model.

${ }^{8}$ Looking at Figure 3, one might conjecture that the increase in the labor supply may be partially explained by the decline in the marginal labor tax, as a result of excluding the capital income from the tax base that is subject to the progressive tax function. To quantify the effect, we conduct a reform experiment in which we use the same progressive tax function as in the benchmark for the labor income in combination with a proportional capital tax, which is adjusted to balance the government budget. The labor supply will rise, but only by $0.7 \%$, implying that most of the rise in the labor supply we find is explained by the labor-dependence in capital taxation. More details of the experiment are contained in Kitao (2010).
} 
rates on age, as shown in Erosa and Gervais (2002) and Garriga (2003) under nonseparable preference of the form used in this paper. Consumption is higher across all age groups, as shown in Figure 2(c).

\subsection{Transition to the reform economy}

The results so far are based on the comparison of two steady states, one implied by the benchmark that approximates the U.S. tax system ("initial steady state") and the other implied by the reformed tax system ("final steady state"). This section studies how the economy responds to the reform and makes a transition to the final steady state. The economy is assumed to be in the initial steady state in period 0 , and at the beginning of period 1, the tax reform is announced and implemented.

Figure 4 displays how the aggregate labor, capital, consumption, the budgetbalancing $\operatorname{tax} \tau_{I}$ and factor prices evolve over time. The two circles in each plot at the first and last period represent the levels in the initial and final steady state respectively. Upon the implementation of the new tax policy, labor supply immediately jumps up by about $5 \%$, while the capital rises only gradually. As a result, capital-labor ratio drops immediately, reducing the wage rate and raising the interest rate. The tax rate $\tau_{I}$ rises by about $0.5 \%$ to cover the lower revenues from capital income taxation, but it gradually falls as the economy approaches the final steady state.

We can also study the welfare effect of the tax reform on generations that are currently alive and ask if the reform can bring a welfare gain for the majority. We compute consumption equivalent variation of agents in different states when the reform is implemented in period 1, which measures the percentage change in consumption in all the possible states for the remainder of their life in the benchmark economy that would make the agent indifferent between the benchmark and the reform economy.

Figure 5 displays the welfare effect of the transition for workers across dimensions of age, assets and the combination of the two. Figure 5(a) shows the welfare effect by age, which is highly related to the change in tax rates faced by households of different ages at the time of the reform. The newborn agents (those at age 20) will benefit from the reform, but the size of the welfare gain is only $0.6 \%$ in consumption equivalence, as opposed to the long-run gain of $1.6 \%$, because the wage rate is lower during the first two decades of transition and the consumption does not reach the level of the final steady state until much later periods. They will also face a higher tax rate $\tau_{I}$ during the transition than in the final steady state. Those negative effects, however, faced by the very young agents during the initial years of the reform are 
offset by the future gain they face as they reach middle-ages and most of them prefer the reform to the status-quo. Households in 20s will face a sudden increase in the capital income tax since their labor income is low, but the effect is relatively small since they do not own many assets. Households in 30s experience a large welfare gain since they face a lower total income tax rates as they benefit from significantly lower capital taxes on the wealth they have begun to accumulate. Thereafter, the welfare gain starts to decline as the capital income tax begins to rise sharply with the fall in labor income. The welfare begins to rise again for households in late 50s and near the retirement age. The social security benefit will be higher after the reform, reflecting the rise in labor supply and payroll tax revenues. In addition, interest rate is also higher during the transition. These positive effects offset and dominate the negative effect from the higher capital taxes for the old-age households near the retirement age.

Figure 5(b) shows that the welfare effect increases in wealth unconditionally. ${ }^{9}$ Figure 5(c) displays the welfare effect across ages for different wealth groups and shows that the positive relationship does not always hold if we condition the effect on age as well. We let households who own wealth of less than twice the average earnings $(\$ 70,000)$ belong to the first group "poor," those with less than ten times the average $(\$ 350,000)$ to group "middle" and the rest to the last group "rich." As discussed above, retirees gain from the rise in social security benefits. The common rise in the retirement benefit implies more utility benefit evaluated in terms of consumption equivalence for the poor households with higher marginal utility. ${ }^{10}$

Among currently alive generations, very few will experience a welfare loss by the reform. More than $95 \%$ of the population will have a welfare gain from the transition to the reform economy. It is often the case that a policy that is desirable in the long-run fails to achieve the majority support of the current generations due to the transition costs. ${ }^{11}$ In the reform that this paper considers, the long-run increase in capital and output does not come at the cost of a temporary drop in the aggregate consumption to raise savings. As shown in Figure 4(c), the consumption also jumps

\footnotetext{
${ }^{9}$ Note that the figure shows some non-smoothness, which is due to the numerical imprecision as the mass at each state with a higher wealth level starts to fall towards the right end of the distribution.

${ }^{10}$ Kitao (2010) presents more detailed analysis on the welfare effect by age as well as the decomposition study on the effect of general equilibrium adjustment along the transition, controlling for the level of social security benefit and factor prices

${ }^{11}$ See for example, Kitao (2008) for the study of entrepreneurial income taxation and Conesa and Krueger (1999) for a social security reform, where the transition cost makes a political support more difficult despite a long-run gain.
} 
up immediately upon the reform, though the full convergence takes a few more decades. The labor supply rises by a large margin immediately, which enables both aggregate capital and consumption to rise simultaneously.

\section{$5 \quad$ Interpretation of results and sensitivity analysis}

This section will discuss how our results relate to the existing theoretical and quantitative work on the optimal capital income taxation in a life-cycle model. It also presents sensitivity analysis on the parametrization of the model, forms of the capital tax function and the effect of general equilibrium adjustment.

\subsection{Theory of optimal income taxation in a life-cycle model and interpretation of results}

Atkeson et al. (1999), Erosa and Gervais (2002) and Garriga (2003) study theoretically the optimal income taxation in a life-cycle model with potentially agedependent labor and capital income taxes. They show that in a typical overlapping generations model, in which optimal labor supply is never constant, the optimal labor income tax is also non-constant. When the labor supply falls, the optimal labor tax is shown to decline as well. Conesa et al. (2009) take a quantitative approach and demonstrate the optimality of a positive and large capital income tax in a full-blown life-cycle model, when the taxes are restricted to be age-independent. They emphasize the role of capital taxation to approximate the age-dependent labor taxation and affect the intertemporal allocation of labor supply.

The optimal profile of capital income taxes differs by the preference specifications. Under the non-separable preference of the form (9) that we considered, the capital tax rate is also non-constant over the life-cycle. Erosa and Gervais (2002) and Garriga (2003) show that the optimal age-dependent capital tax rates rise from negative to positive in a model that exhibits a hump-shaped labor supply profile. When the labor taxes cannot be conditioned on age, age-dependent capital taxation can mimic the role of age-dependent labor taxation. This result holds under general preference. $^{12}$

Labor-dependent capital taxation that we proposed in this paper can approximate the profiles of age-dependent taxation on both labor and capital. In order

\footnotetext{
${ }^{12}$ In Kitao (2010), we discuss these results and intuition in more details using simple two and three period models with separable and non-separable preference. It also provides all the algebra and more detailed description of the results presented in this section.
} 
to highlight the intuition, consider a simple stationary model in which a household of age $j$ chooses consumption $c_{j}$, saving $s_{j+1}$ and labor supply $l_{j}$ to maximize the present discounted value of utility, $U\left(c_{j}, l_{j}\right)$, satisfying regular conditions. Ignore any uncertainty or borrowing constraint. Denote the interest rate as $r$ and normalize the wage to 1 . Denoting labor and capital income tax at each age as $\tau_{l_{j}}$ and $\tau_{k_{j}}$ and labor productivity as $\varepsilon_{j}$ the intertemporal optimality condition with respect to labor supply is given as

$$
\frac{\varepsilon_{j+1}}{\varepsilon_{j}} \frac{U_{l_{j}}}{U_{l_{j+1}}}=\beta\left[1+r\left(1-\tau_{k_{j+1}}\right)\right] \frac{1-\tau_{l_{j}}}{1-\tau_{l_{j+1}}} .
$$

Consider the case where the optimal labor tax falls in age, that is, $\tau_{l_{j}}>\tau_{l_{j+1}}$. In the absence of age dependence, a positive capital income tax can generate the same intertemporal wedge created by the labor-dependent labor taxation. Suppose that the optimal labor tax falls at an increasing rate and the optimal wedge defined as $\omega_{j}=\left(1-\tau_{l_{j}}\right) /\left(1-\tau_{l_{j+1}}\right)$ increases in age. In such a case, age-dependent capital taxes that increase in age can mimic the role of non-constant wedges generated by the age-dependent labor taxes. A flat capital tax can only generate a single wedge.

Now consider labor-dependent capital taxation of the form that this paper studied, that is, the capital income tax is a decreasing function of labor income. Intertemporal optimality conditions read as

$$
\begin{aligned}
\frac{\varepsilon_{j+1}}{\varepsilon_{j}} \frac{U_{l_{j}}}{U_{l_{j+1}}} & =\beta\left[1+r\left(1-\tau_{k}\left(\varepsilon_{j+1} l_{j+1}\right)\right)\right] \frac{\left(1-\tau_{l_{j}}\right)-r \tau_{k}^{\prime}\left(\varepsilon_{j} l_{j}\right) s_{j}}{\left(1-\tau_{l_{j+1}}\right)-r \tau_{k}^{\prime}\left(\varepsilon_{j+1} l_{j+1}\right) s_{j+1}} \\
\frac{U_{c_{j}}}{U_{c_{j+1}}} & =\beta\left[1+r\left(1-\tau_{k}\left(\varepsilon_{j+1} l_{j+1}\right)\right)\right]
\end{aligned}
$$

The additional term $\left(-r \tau_{k}^{\prime} s\right)>0$ on the RHS reflects the reduction in capital tax payment on savings, which is added to the after-tax wage $\left(1-\tau_{l}\right)$ to constitute the effective wage rate at each age. In the part of the life-cycle where households accumulate wealth, this additional benefit of work will rise as well, generating an intertemporal wedge. Therefore, in the absence of age-dependence, the role of agedependent labor income taxes that fall in age can be mimicked by labor-dependent capital taxation. Essentially, both taxes generate a profile of increasing net benefit of work and induce more work effort at older ages.

There is an additional direct effect of labor-dependent capital taxation on the intertemporal labor and consumption decisions. When the labor income falls, the capital income tax increases due to the negative cross-partial of the tax function. The implied profile of capital tax rates mimics the shape of the optimal age-dependent 
capital taxes that increase in age in the part of the life-cycle where the labor income declines. Rising capital taxes make the future consumption increasingly more costly and induce more work effort in later periods.

In the absence of age-dependence, labor-dependent capital taxation can mimic the age-dependent labor taxes through two channels, one through the rising capital tax rates and the other through the rising effective wages. It does not have to rely solely on a single flat capital tax to approximate the intertemporal wedge implied by the optimal age-dependent labor taxes. Conesa et al. (2009) find the optimal capital tax rate to be positive and significantly high at $36 \%$. The degree of capital taxation involves a tradeoff between the role to approximate age-dependent labor taxes and the distortions on households' saving decision. The high capital tax significantly discourages the saving and the aggregate capital falls by as much as $7 \%$ under the optimal tax system of Conesa et al. (2009). Introducing the labor-dependence provides the possibility of mitigating the negative general equilibrium consequence on aggregate capital and output. ${ }^{13}$

\subsection{Sensitivity to preference parameters}

In this subsection, we study sensitivity of our results to the degree of risk aversion and labor supply elasticity and study sensitivity of our results. ${ }^{14}$ Results are summarized in Table 3.

First, we compare the results with the value of parameter $\sigma$ in the preference of the form (9), set at 2, 4 (baseline) and 6, which imply coefficient of relative risk aversion (CRRA) at 1.4, 2.1 and 2.8 respectively. The models exhibit same qualitative effects, while quantitative effects somewhat differ. With a higher CRRA (and lower intertemporal elasticity of substitution), households care more about the smoothness of consumption and leisure over the life-cycle and respond less to the reform, though even with $\sigma=6$, the capital increases by as much as $5.7 \%$, only slightly less than $6.1 \%$ in the baseline model. Other variables change by a similar magnitude across three different values of $\sigma$.

Second, in order to quantify the sensitivity to the labor supply elasticity, we

\footnotetext{
${ }^{13}$ A positive capital tax and labor-dependent capital taxation are not the only ways to approximate the optimal age-dependent labor taxation. In a recent work, Gervais (2009) focuses on the progressivity imbedded in the U.S. tax system and its role to mimic the role of age-dependent taxation.

${ }^{14}$ In each model, we recalibrate the parameters to match the same aggregate statistics that we used as calibration targets, namely the value of the subjective discount factor $\beta$, preference parameter $\nu$ and TFP parameter $A$.
} 
consider a preference that is separable in consumption and leisure, that allows us to pin down the value of labor supply elasticity.

$$
\frac{c^{1-\sigma_{1}}}{1-\sigma_{1}}+\chi \frac{(1-l)^{1-\sigma_{2}}}{1-\sigma_{2}}
$$

We set the value of $\sigma_{1}$ at 2 , which implies the degree of relative risk aversion equivalent to the baseline model. $\sigma_{2}$ is set at different values of 4,2 and 1 , which imply the average Frisch elasticity of $0.5,1.0$ and 2.0 respectively. The middle value of $\sigma_{2}$ implies the degree of labor supply elasticity as in the baseline model.

The reform effect on labor supply declines in labor supply elasticity, from a $2.4 \%$ increase under high elasticity of 2.0 to $1.5 \%$ under elasticity of 0.5 . Aggregate capital increases by the same degree, from 3.8 to $4.3 \%$. Since agents care more about the smoothness of the labor supply as the elasticity falls, a flatter labor supply profile across ages induced by the reform is appreciated more and the long-run welfare effect is larger.

In general, the effects are qualitatively the same under the separable preference as those under the non-separable preference, but the effects are somewhat suppressed quantitatively. For example, comparing the separable case with $\sigma_{2}=2$ and the

non-separable case with $\sigma=4$, both of which imply CRRA and Frisch elasticity of approximately 2 and 1 respectively, the change in aggregate capital is 3.9 vs $6.1 \%$ and the long-run welfare gain is 0.9 vs $1.6 \%$. Non-separable preference of the form (9) implies a complementarity between consumption and labor supply, i.e. $u_{l, c}>0$, when the value of $\sigma$ is greater than unity. Therefore, the reform's positive effects on both variables reinforce each other and the quantitative effects are magnified.

\subsection{Sensitivity to the specification of capital tax function}

This section considers alternative values of the parameters that enter the capital tax function (11). First, we study the sensitivity to the slope of the capital tax function $\tau_{k}^{\prime}\left(y_{L}\right)=\phi_{1}$ and vary it from -3.0 to 1.0 . We let all the tax functions pass through the reference point of the average tax rate of $22 \%$ at the average labor income of the benchmark economy and the intercept parameter $\phi_{0}$ is determined accordingly. Second, we study the sensitivity to the level of the capital tax function, by shifting the tax schedule up and down in a parallel manner. Keeping the slope parameter $\phi_{1}$ fixed at the baseline level of -1 , we vary the parameter $\phi_{0}$ from 0.3 to 1.0 , that is, the highest capital tax at zero labor income ranges from 30 to $100 \%$.

The results for the sensitivity to the slope is summarized in Table 4 . If the capital tax falls more steeply in labor income ( $\phi_{1}$ is more negative), aggregate effects are 
magnified. In reform $\mathrm{B}$, where the slope $\phi_{1}$ is doubled in the absolute value to -2.0, aggregate capital and labor will rise by as much as 11.3 and $7.5 \%$, relative to 6.1 and $4.3 \%$ in the baseline reform C. In reform $\mathrm{D}$, where the capital income is taxed at a proportional rate, aggregate capital will still increase slightly relative to the benchmark U.S. tax system. This is because the disincentive effect on savings associated with the progressive income tax schedule is eliminated. In reform E, the slope parameter $\phi_{1}$ is positive, that is, the capital tax linearly increases in labor income. Both work and saving are significantly discouraged under the tax system.

The last rows of Table 4 display welfare effects of reforms in the long and shortrun. The effects are not monotonic in the slope of the capital tax function. When the negative labor-dependence is introduced, there is always a sizeable welfare gain in the long-run across different slopes we considered. It is worth noting that the longrun welfare falls in reform A relative to reform B, while all the aggregate variables are higher. In general, positive welfare effects come from the utility gain from higher consumption that more than offsets higher disutility from additional hours of work. When both consumption and labor supply keep rising, marginal utility of consumption starts to decline while the marginal disutility from work continues to rise. Hence, exploiting the additional work incentive with more negative slope of the capital tax function becomes more costly in terms of welfare.

Short-run effects are very different from long-run effects. The welfare of a newborn agent at the time of the reform will deteriorate as the tax function becomes steeper and there will be a welfare loss of $1.0 \%$ in reform A. Under this reform, the wage falls by about $4 \%$ immediately upon the reform announcement and it takes about 15 years before it returns to the pre-reform level and another few decades to fully converge to the long-run level. ${ }^{15}$ The proportional labor tax rate $\tau_{I}$ also has to rise during the transition. As a result, more young agents experience a welfare loss from the transition and the fraction of the population that gain from the reform falls to $60.5 \%$.

The results for the sensitivity to the level of the capital tax function are summarized in Table 5. Aggregate capital falls in the level of capital taxation but the labor supply goes in the other direction. As we discussed in section 5.1, a high capital tax induces more work effort, especially at older ages, since it increases the cost of future consumption and the opportunity cost of leisure. With a higher level of capital tax, the rise in aggregate labor contributes to a higher level of consumption and the long-run welfare is higher in reform III and IV. A further rise in capital taxation will

\footnotetext{
${ }^{15}$ The figures for the transition dynamics of sensitivity experiments are not displayed in the paper but available from the author upon request.
} 
start to reduce the consumption and with the rise of the marginal disutility from work the long-run welfare will fall under reform $\mathrm{V}$.

A new-born will gain more from the transition to the economy with a higher capital tax. They do not own assets and are not subject to the high capital tax at least immediately while they enjoy lower labor income taxes as a result of increased revenues from capital taxation. Although the wage will fall significantly in the longrun due to a massive decline in capital as in reform IV and V, it does not jump to the final steady state level immediately since the capital can fall only gradually. The average welfare for workers will be lower under the higher level of capital taxation, since older workers at the time of the reform will experience a severe welfare loss with a sudden decline in the return on the accumulated wealth.

\subsection{Role of price adjustments: partial equilibrium analysis}

In order to understand the role of general equilibrium effects of price adjustment, we conduct a reform experiment under the partial equilibrium assumption, holding the interest rate and wage fixed at the benchmark level during the transition and in the final steady state. Table 6 summarizes the results. Since the interest rate is pinned at the higher level of $4.0 \%$, households increase saving and aggregate capital will rise by $8.2 \%$, more than the rise of $6.2 \%$ under general equilibrium. There is not a large change in the steady state welfare, but the transitional welfare gain is higher for the new-born at the time of the reform since they would not suffer from the lower wage rate during the transition.

Although the effects are not too different quantitatively since the capital-labor ratio does not vary much under general equilibrium with the rise in capital and labor offsetting each other, price adjustments can play a greater role under alternative policy experiments which imply a larger change in the capital-labor ratio. ${ }^{16}$

\section{Conclusion}

The paper studied a capital income tax that declines in labor supply through its negative dependence on labor income. It is shown that such a system provides an ample incentive to work harder and save more, especially for households of middle to old ages who possess high labor productivity and wealth and induces more efficient allocation of labor supply over the life-cycle. The reform brings a sizeable welfare

\footnotetext{
${ }^{16}$ Kitao (2010) presents additional partial equilibrium experiments for the reforms with different levels of capital tax that had a larger effect on factor prices.
} 
gain in the long-run in the magnitude of $1.6 \%$ in consumption equivalent variation. By computing the transition dynamics, we showed that a great majority of currently alive generations would experience a welfare gain.

There are several extensions that future research should investigate. Existing studies on income taxation in life-cycle models focus on intensive labor supply responses and it is not well known how allowing for endogenous labor participation and retirement decision will impact the analysis. Also, extending the model to incorporate additional heterogeneity among households such as multiple education levels will be a natural extension and searching for the optimal tax schedule in such a model under some parametric class of functions will be worth exploring despite a computational challenge.

As a final remark, one may question practicality of such a reform in light of its apparent complexity. The tax authority, however, only needs the information on capital and labor income, nothing more than what the existing U.S. tax system asks for. What is critical in generating various incentive effects is the simple mechanism in which additional work effort increases the net return from savings. A linear and smooth function considered in this paper is one of the possibilities. We believe that the system may indeed have a merit in its simplicity relative to the existing intricate tax system. 


\section{References}

Aiyagari, S. R. (1995). Optimal capital income taxation with incomplete markets, borrowing constraints, and constant discounting. Journal of Political Economy 103(6), 1158-1175.

Altig, D., A. J. Auerbach, L. J. Kotlikoff, K. A. Smetters, and J. Walliser (2001). Simulating fundamental tax reform in the United States. American Economic Review 91 (3), 574-595.

Atkeson, A., V. Chari, and P. Kehoe (1999). Taxing capital income: A bad idea. Federal Reserve Bank of Minneapolis, Quarterly Review 23(3), 3-17.

Attanasio, O. P. (1999). Consumption. In J. B. Taylor and M. Woodford (Eds.), Handbook of Macroeconomics, Volume 1, Chapter 11. Amsterdam: NorthHolland.

Auerbach, A. J. and L. J. Kotlikoff (1987). Dynamic Fiscal Policy. Cambridge: Cambridge University Press.

Bell, F. C. and M. L. Miller (2002). Life tables for the United States social security area 1900-2100. Actuarial Study 116, Office of the Chief Actuary, Social Security Administration.

Bohacek, R. and M. Kejak (2004). Optimal government policies in models with heterogeneous agents. Working Paper, CERGE-EI.

Chamley, C. (1986). Optimal taxation of capital income in general equilibrium with infinite lives. Econometrica 54(3), 607-622.

Conesa, J. C., S. Kitao, and D. Krueger (2009). Taxing capital? Not a bad idea after all! American Economic Review 99(1), 25-48.

Conesa, J. C. and D. Krueger (1999). Social security with heterogeneous agents. Review of Economic Dynamics 2(4), 757-795.

Conesa, J. C. and D. Krueger (2006). On the optimal progressivity of the income tax code. Journal of Monetary Economics 53(7), 1425-1450.

Domeij, D. and J. Heathcote (2004). On the distributional effects of reducing capital taxes. International Economic Review 45(2), 523-554.

Erosa, A. and M. Gervais (2002). Optimal taxation in life-cycle economies. Journal of Economic Theory 105(2), 338-369.

Garriga, C. (2003). Optimal fiscal policy in overlapping generations models. Working Paper, Florida State University. 
Gervais, M. (2009). On the optimality of age-dependent taxes and the progressive U.S. tax system. Working Paper, University of Southampton.

Gouveia, M. and R. P. Strauss (1994). Effective federal individual income tax functions: an exploratory empirical analysis. National Tax Journal 47(2), 317339.

Hansen, G. D. (1993). The cyclical and secular behaviour of the labour input: Comparing efficiency units and hours worked. Journal of Applied Econometrics 8(1), 71-80.

Heathcote, J., K. Storesletten, and G. L. Violante (2004). The macroeconomic implications of rising wage inequality in the United States. Working Paper, New York University.

Hubbard, R. G. and K. Judd (1986). Liquidity constraints, fiscal policy, and consumption. Brookings Papers on Economic Activity (1), 1-50.

İmrohoroğlu, S. (1998). A quantitative analysis of capital income taxation. International Economic Review 39(2), 307-328.

Jones, L. E., R. E. Manuelli, and P. E. Rossi (1993). Optimal taxation in models of endogenous growth. Journal of Political Economy 101 (3), 485-517.

Judd, K. L. (1985). Redistributive taxation in a simple perfect foresight model. Journal of Public Economics 28(1), 59-83.

Kitao, S. (2008). Entrepreneurship, taxation and capital investment. Review of Economic Dynamics 11(1), 44-69.

Kitao, S. (2010). Supplemental document for "labor-dependent capital income taxation that encourages work and saving". available online at http://sites.google.com/site/sagirikitao/research3.

Lucas, R. E. (1990). Supply-side economics: An analytical review. Oxford Economic Papers 42(2), 293-316.

Nishiyama, S. and K. Smetters (2005). Consumption taxes and economic efficiency with idiosyncratic wage shocks. Journal of Political Economy 113(5), 10881115 .

Tauchen, G. (1986). Finite state Markov-chain approximations to univariate and vector autoregressions. Economics Letters 20(2), 177-181.

Ventura, G. (1999). Flat tax reform: A quantitative exploration. Journal of Economic Dynamics \& Control 23(9-10), 1425-1458. 


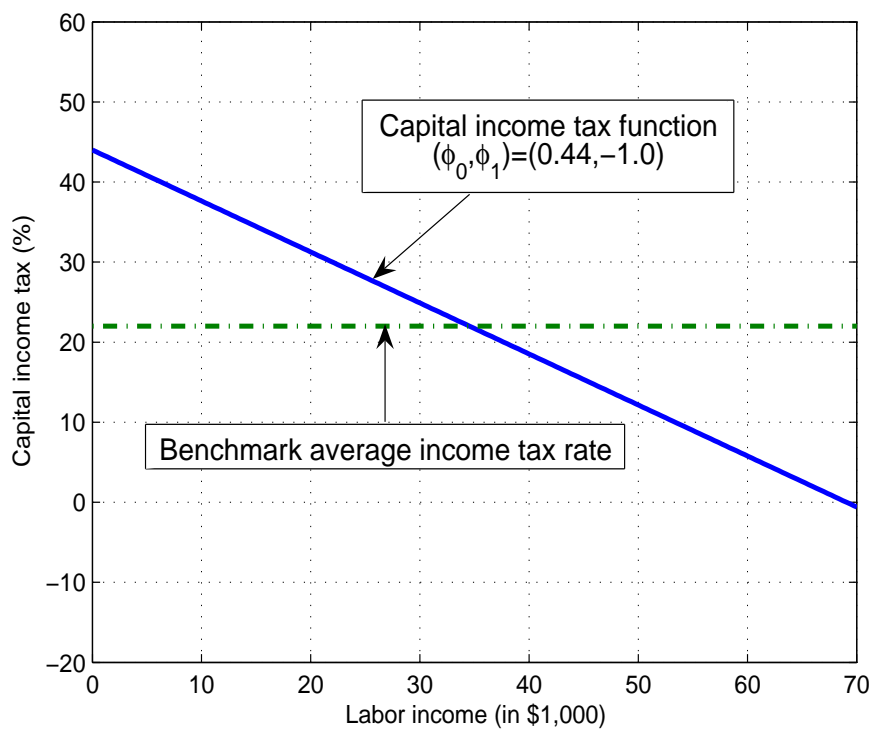

Figure 1: Capital income tax function under the reform 


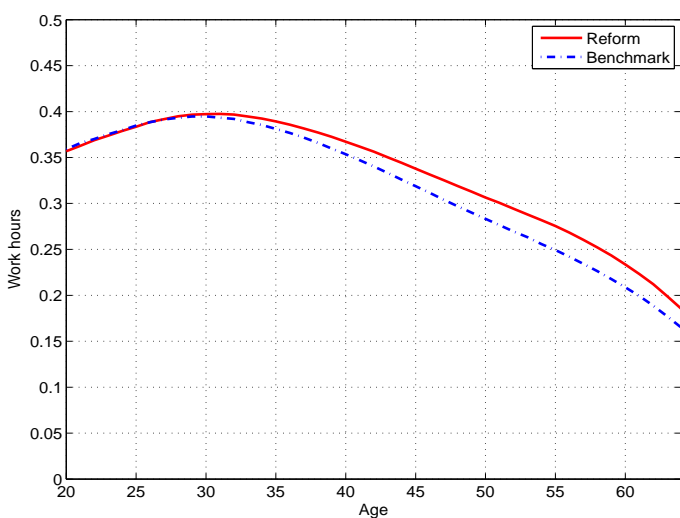

(a) Labor supply

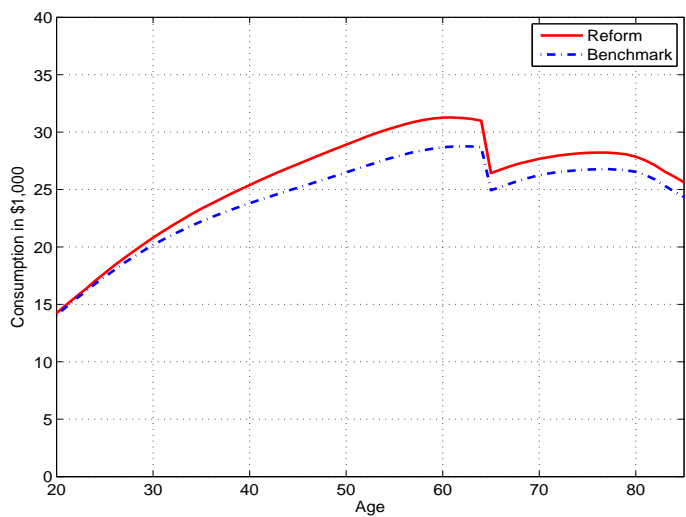

(c) Consumption

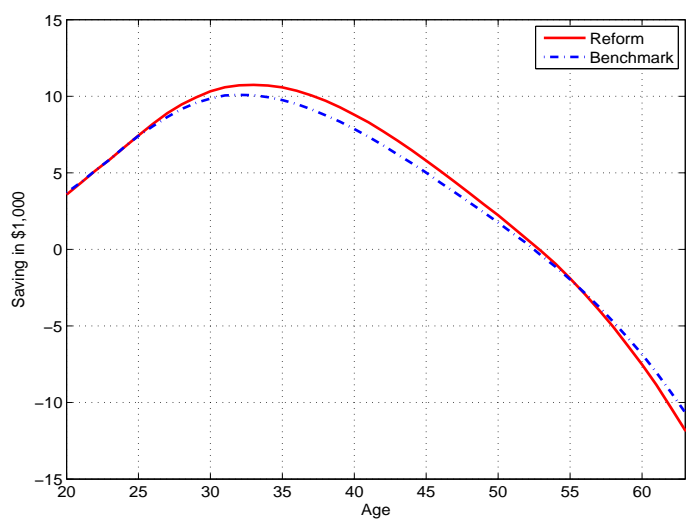

(b) Saving

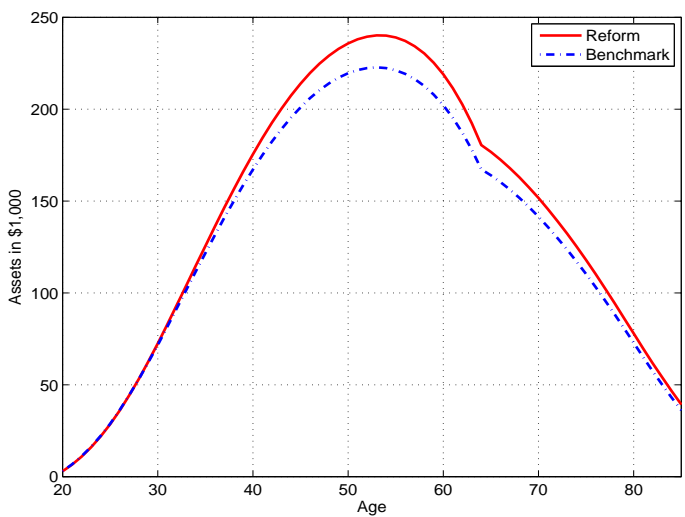

(d) Assets

Figure 2: Life-cycle profiles in benchmark and reform 

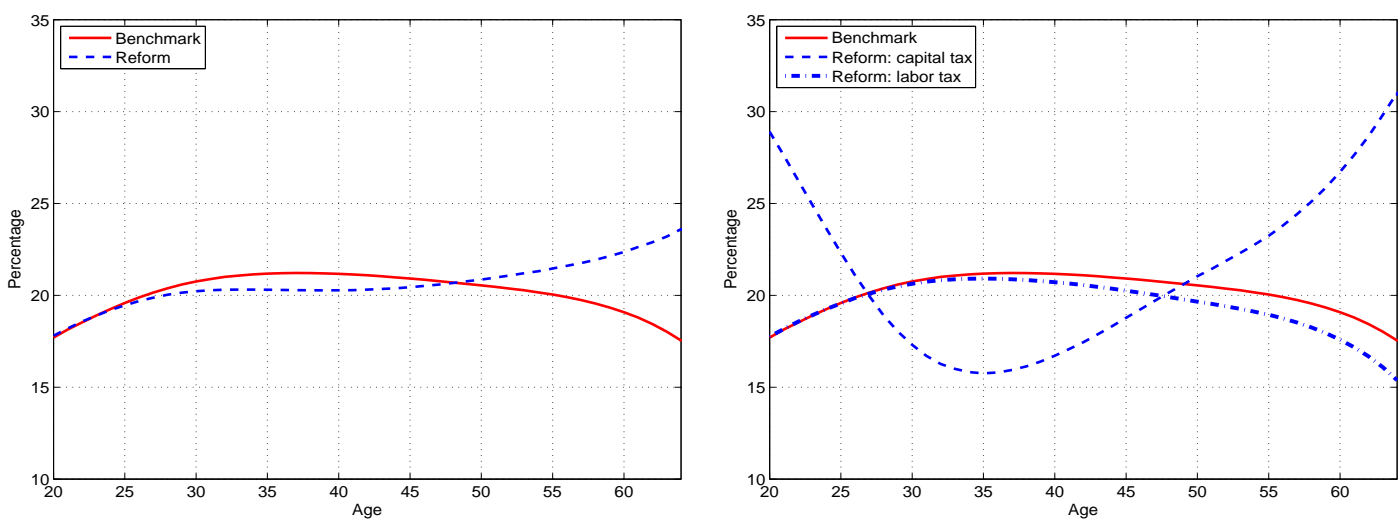

(a) Total income tax rates in benchmark and (b) Total income tax rates in benchmark and reform capital and labor income tax rates in reform

Figure 3: Tax rates by age 


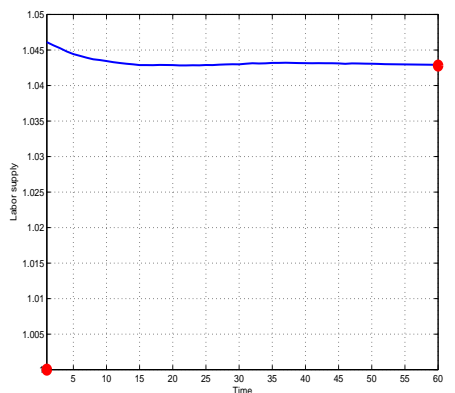

(a) Labor $L$

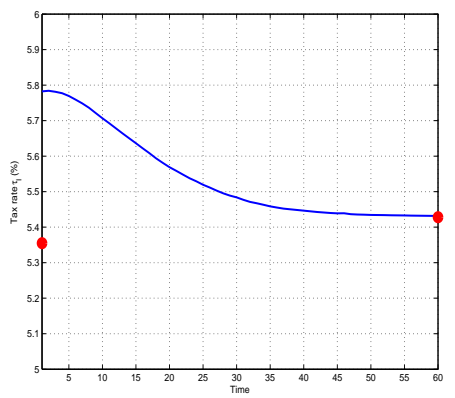

(d) Tax rate $\tau_{I}$

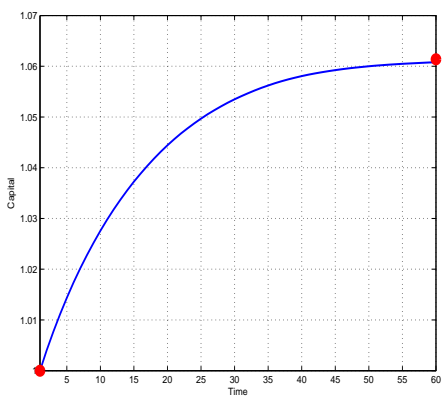

(b) Capital $K$

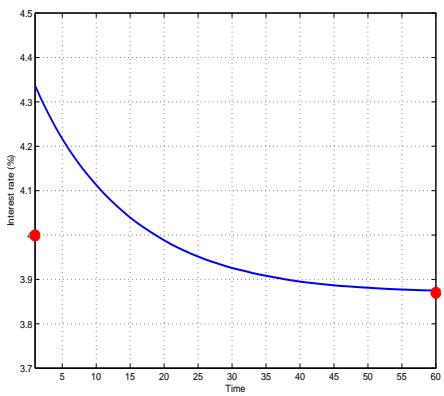

(e) Interest rate $r$

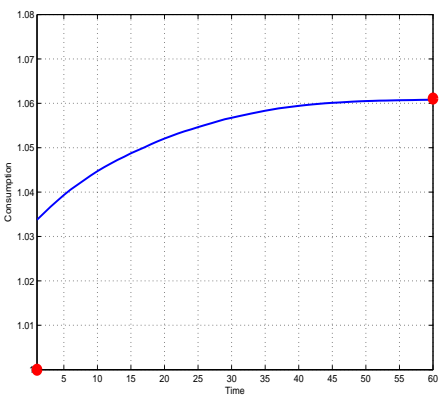

(c) Consumption $C$

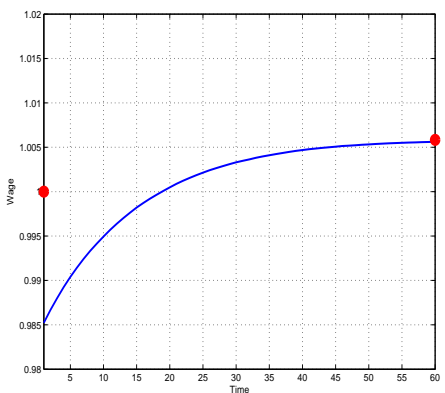

(f) Wage $w$

Figure 4: Transition of aggregate variables: two circles at the first and last periods denote the levels in the initial and final steady states. The level variables $(L, K$, $C$ and $w)$ are normalized so that they take the value of unity in the initial steady state. 


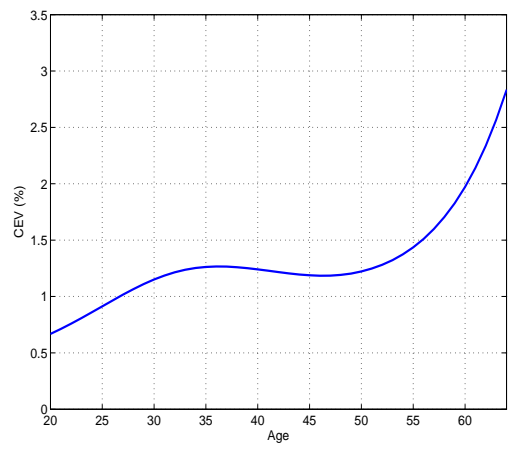

(a) Welfare effect across ages

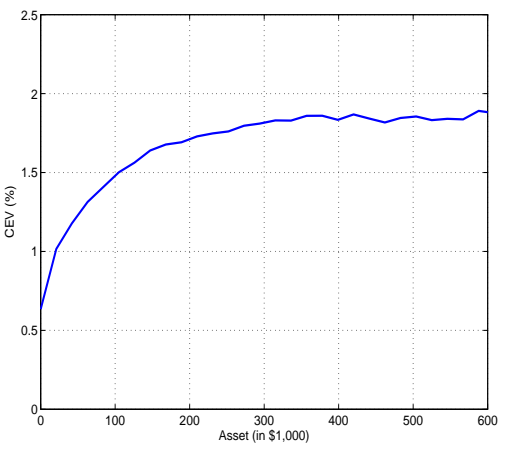

(b) Welfare effect across assets

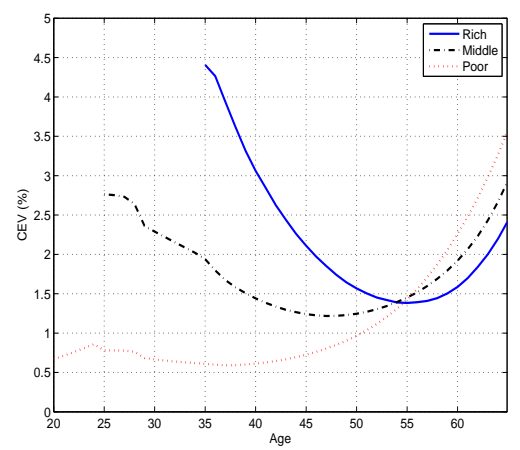

(c) Welfare effect across ages by wealth group

Figure 5: Welfare effect of the transition: the figures display the welfare effects on workers evaluated in terms of consumption equivalent variation (CEV) across ages and asset levels. 
Table 1: Benchmark calibration

\begin{tabular}{|c|c|c|}
\hline \multicolumn{3}{|l|}{ Demographics } \\
\hline Maximum age & $J$ & 81 (100 years old) \\
\hline Retirement age & $j_{R}$ & 46 (65 years old) \\
\hline Population growth rate & $n$ & 0.012 \\
\hline Conditional survival rates & $s_{j}$ & Bell and Miller (2002) \\
\hline \multicolumn{3}{|l|}{ Labor productivity } \\
\hline Age-specific efficiency & $\varepsilon_{j}$ & Hansen (1993) \\
\hline \multirow[t]{2}{*}{ Idiosyncratic risk: $\mathrm{AR}(1)$ process } & $\rho$ & 0.94 \\
\hline & $\sigma_{e}^{2}$ & 0.02 \\
\hline \multicolumn{3}{|l|}{ Technology } \\
\hline Capital share parameter & $\alpha$ & 0.33 \\
\hline Depreciation rate & $\delta$ & 0.07 \\
\hline TFP & $A$ & normalization \\
\hline \multicolumn{3}{|l|}{ Preference } \\
\hline Discount factor & $\beta$ & 1.008 \\
\hline Preference weight on consumption & $\nu$ & 0.368 \\
\hline Curvature parameter & $\sigma$ & 4.0 \\
\hline \multicolumn{3}{|l|}{ Government } \\
\hline \multirow{3}{*}{$\begin{array}{l}\text { Consumption tax } \\
\text { Income tax function }\end{array}$} & $\tau_{c}$ & 0.05 \\
\hline & $\left\{\kappa_{0}, \kappa_{1}\right\}$ & $\{0.258,0.768\}$ \\
\hline & $\tau_{I}$ & 0.054 \\
\hline Social security tax & $\tau_{s s}$ & 0.106 \\
\hline Social security benefit & ss & 46 percent of average labor income \\
\hline Government expenditures & $G$ & 20 percent of aggregate output \\
\hline
\end{tabular}


Table 2: Aggregate effects of the tax reform

\begin{tabular}{|l|c|c|}
\hline & Benchmark & Reform \\
\hline Output $Y$ & - & $+4.9 \%$ \\
Capital $K$ & - & $+6.1 \%$ \\
Labor $L$ & - & $+4.3 \%$ \\
Work hours & - & $+3.6 \%$ \\
Consumption $C$ & - & $+6.1 \%$ \\
Wage & - & $+0.6 \%$ \\
Interest rate & $4.0 \%$ & $3.9 \%$ \\
$\tau_{I}$ & $5.4 \%$ & $5.4 \%$ \\
\hline Average income tax rate & $21.8 \%$ & $20.7 \%$ \\
$\quad$ - workers & $22.0 \%$ & $20.8 \%$ \\
$\quad$ - retirees & $13.3 \%$ & $13.9 \%$ \\
\hline CEV & - & $+1.6 \%$ \\
\hline
\end{tabular}


Table 3: Sensitivity to preference specifications

\begin{tabular}{|l|c|c|c|c|c|c|}
\hline Preference & \multicolumn{3}{|c|}{ Non-separable } & \multicolumn{3}{c|}{ Separable } \\
\hline$\sigma$ (Non-sep) and $\sigma_{2}$ (Sep.) & 2 & 4 & 6 & 4 & 2 & 1 \\
\hline CRRA & 1.4 & 2.1 & 2.8 & 2.0 & 2.0 & 2.0 \\
Frisch elasticity & 1.4 & 1.1 & 0.9 & 0.5 & 1.0 & 2.0 \\
\hline Capital $K$ & $+7.2 \%$ & $+6.1 \%$ & $+5.7 \%$ & $+3.8 \%$ & $+3.9 \%$ & $+4.0 \%$ \\
Labor $L$ & $+4.6 \%$ & $+4.3 \%$ & $+4.1 \%$ & $+1.5 \%$ & $+2.0 \%$ & $+2.4 \%$ \\
Work hours & $+3.7 \%$ & $+3.6 \%$ & $+3.6 \%$ & $+1.2 \%$ & $+1.6 \%$ & $+1.9 \%$ \\
Consumption $C$ & $+6.7 \%$ & $+6.1 \%$ & $+5.8 \%$ & $+2.4 \%$ & $+3.0 \%$ & $+3.5 \%$ \\
Wage & $+0.8 \%$ & $+0.6 \%$ & $+0.5 \%$ & $+0.7 \%$ & $+0.6 \%$ & $+0.5 \%$ \\
\hline CEV (steady state, ex-ante) & $+2.1 \%$ & $+1.6 \%$ & $+1.2 \%$ & $+1.2 \%$ & $+0.9 \%$ & $+0.6 \%$ \\
CEV (transition, new-born) & $+1.1 \%$ & $+0.6 \%$ & $+0.2 \%$ & $+0.7 \%$ & $+0.5 \%$ & $+0.1 \%$ \\
\hline
\end{tabular}


Table 4: Sensitivity to the slope of capital tax function

\begin{tabular}{|l|r|r|r|r|c|}
\hline & & & Baseline & & \\
& \multicolumn{1}{|c|}{$\mathrm{A}$} & $\mathrm{B}$ & \multicolumn{1}{c|}{$\mathrm{C}$} & $\mathrm{D}$ & $\mathrm{E}$ \\
\hline$\phi_{1}$ & -3.0 & \multicolumn{1}{|c|}{-2.0} & \multicolumn{1}{c|}{-1.0} & \multicolumn{1}{c|}{0.0} & \multicolumn{1}{c|}{1.0} \\
\hline Capital $K$ & $+16.6 \%$ & $+11.3 \%$ & $+6.1 \%$ & $+1.4 \%$ & $-3.0 \%$ \\
Labor $L$ & $+10.2 \%$ & $+7.5 \%$ & $+4.3 \%$ & $+0.5 \%$ & $-3.5 \%$ \\
Wage & $+1.9 \%$ & $+1.1 \%$ & $+0.6 \%$ & $+0.3 \%$ & $+0.3 \%$ \\
$\tau_{I}(\%)$ & $7.6 \%$ & $6.1 \%$ & $5.4 \%$ & $5.7 \%$ & $7.0 \%$ \\
\hline CEV (steady state, ex-ante) & $+1.8 \%$ & $+2.1 \%$ & $+1.6 \%$ & $+0.2 \%$ & $-2.1 \%$ \\
CEV (transition, new-born) & $-1.0 \%$ & $+0.3 \%$ & $+0.6 \%$ & $-0.1 \%$ & $-1.6 \%$ \\
CEV (transition, all workers) & $+1.5 \%$ & $+1.7 \%$ & $+1.3 \%$ & $+0.2 \%$ & $-1.5 \%$ \\
\% of CEV>0 (transition) & $60.5 \%$ & $82.7 \%$ & $96.3 \%$ & $74.4 \%$ & $3.1 \%$ \\
\hline
\end{tabular}

Note: All the tax functions pass through the reference point of the average tax rate $22 \%$ at the average labor income of the benchmark economy. 
Table 5: Sensitivity to the level of capital tax

\begin{tabular}{|l|r|r|r|r|r|}
\hline & I & $\begin{array}{c}\text { Baseline } \\
\text { II }\end{array}$ & III & IV & \multicolumn{1}{c|}{ V } \\
\hline$\phi_{0}$ & \multicolumn{1}{c|}{0.30} & \multicolumn{1}{c|}{0.44} & \multicolumn{1}{c|}{0.60} & \multicolumn{1}{c|}{0.80} & \multicolumn{1}{c|}{1.00} \\
\hline Capital $K$ & $+8.8 \%$ & $+6.1 \%$ & $+2.3 \%$ & $-4.1 \%$ & $-13.4 \%$ \\
Labor $L$ & $+3.2 \%$ & $+4.3 \%$ & $+5.6 \%$ & $+7.3 \%$ & $+9.0 \%$ \\
Consumption $C$ & $+5.1 \%$ & $+6.1 \%$ & $+7.1 \%$ & $+8.0 \%$ & $+7.8 \%$ \\
Wage & $+1.8 \%$ & $+0.6 \%$ & $-1.1 \%$ & $-3.6 \%$ & $-7.3 \%$ \\
Interest rate & $3.6 \%$ & $3.9 \%$ & $4.2 \%$ & $4.9 \%$ & $5.8 \%$ \\
$\tau_{I}$ (\%) & $7.4 \%$ & $5.4 \%$ & $3.0 \%$ & $-0.3 \%$ & $-4.0 \%$ \\
\hline CEV (steady state, ex-ante) & $+0.9 \%$ & $+1.6 \%$ & $+2.1 \%$ & $+2.2 \%$ & $+1.2 \%$ \\
CEV (transition, new-born) & $-0.4 \%$ & $+0.6 \%$ & $+1.6 \%$ & $+2.6 \%$ & $+2.9 \%$ \\
CEV (transition, all workers) & $+1.2 \%$ & $+1.3 \%$ & $+1.3 \%$ & $+1.0 \%$ & $+0.4 \%$ \\
\% of CEV>0 (transition) & $23.6 \%$ & $96.3 \%$ & $89.6 \%$ & $79.1 \%$ & $67.8 \%$ \\
\hline
\end{tabular}

Note: All the tax functions have the same slope, $\phi_{1}=-1.0$. If the labor income is at the average of the benchmark, the capital tax rate is $8 \%, 22 \%, 38 \%, 58 \%$ and $78 \%$ in Reform I to $\mathrm{V}$, respectively. 
Table 6: Reform effects under general vs partial equilibrium

\begin{tabular}{|l|c|r|}
\hline & General eq. & Partial eq. \\
\hline Capital $K$ & $+6.1 \%$ & $+8.2 \%$ \\
Labor $L$ & $+4.3 \%$ & $+4.1 \%$ \\
Wage & $+0.6 \%$ & unch. \\
Interest rate & $-0.13 \%$-pt & unch. \\
\hline CEV (steady state, ex-ante) & $+1.6 \%$ & $+1.8 \%$ \\
CEV (transition, new-born) & $+0.6 \%$ & $+1.0 \%$ \\
\hline
\end{tabular}

